Thus a solution containing I 00 milligrams of mixed carbohydrates, using the factor 0.00386 , if it formed 200 milligrams cupric oxide by reduction of the Fehling solution in the manner above described, would have a cupric reducing power, or $K_{3.86}$ of 90.68 .

Massachusetts Institute of Technology, Boston, Mass.

\title{
ALUMINUM ANALYSIS.
}

BY JAMES OTIS HANDY.

Received June 30,2896 .

L THOUGH the aluminum industry is not a large one
in the sense that the iron industry is, it is growing
very rapidly. The output of the United States in I894 was 550,000 pounds, and in 1895 it was about 850,000 pounds. The Pittsburg Reduction Company, with works at New Kensington, near Pittsburg, $\mathrm{Pa}$, and at Niagara Falls, N. $\mathrm{Y}$., is the only American producer of aluminum. The material is made by the electrolysis, in carbon-lined pots, of alumina dissolved in a fused bath of fluorides. The product of each pot is ladled out at intervals and is graded according to the analyses of the Pittsburgh Testing Laboratory, Limited. Some of the aluminum is sold as it is made and some is alloyed to modify its physical properties. Alloys of aluminum with three per cent. nickel, or with three to seven per cent. copper, or similar amounts of zinc are very useful on account of increased strength with only slightly increased specific gravity. The aluminum at present produced with the best ores available contains from

99 to 99.9 per cent. of aluminum.

0.3 to 0.05 per cent. of silicon (combined and graphitic).

0.50 to 0.0 per cent. of copper.

0.20 to 0.0 per cent. of iron.

Carbon is sometimes present in aluminum.

Second grade aluminum contains ninety-six to ninety-eight per cent. aluminum, silicon and iron making up the remainder. Aside from analyses of metallic aluminum, there are required in the pursuit of the aluminum industry, analyses of alloys of copper, nickel, manganese, chromium, tungsten, zinc, and tita- 
nium, with aluminum; aluminum solders, containing tin, zinc, and phosphorus; aluminum hydrate, bauxite, and electrode carbons; hydrofluoric acid and fluorides.

ANALYSIS OF COMMERCIAL ALUMINUM. (95 to 99.9 PER CENT. PURE).

In the analysis of aluminum we are offered a choice of solvents.

Solubility of Aluminum: Hydrochloric acid of thirty-three per cent., (i.e., one part of hydrochloric acid of $1.2 \mathrm{sp}$. gr. to two parts water) is a rapid solvent.

Sulphuric acid of twenty-five per cent. dissolves aluminum completely on long boiling.

Nitric acid of one and two-tenths specific gravity dissolves aluminum on prolonged boiling.

Acid mixture: A mixture of the three acids which ... - term "Acid Mixture" is made of

IOO cc. nitric acid of I.42 sp. gr.

$300 \mathrm{cc}$. hydrochloric acid of I. $20 \mathrm{sp}$. gr.

$600 \mathrm{cc}$. sulphuric acid of twenty-five per cent.

It is a very useful solvent for aluminum because it supplies oxidizing conditions during solution and so prevents loss of combined silicon as hydride. The sulphuric acid content of the acid mixture furnishes a means of rapidly dehydrating the silica.

Sodium hydroxide solution of thirty-three per cent. is a useful solvent when it is desired to separate the metallic impurities from the bulk of the aluminum at once. Weaker solutions do not work as quickly or completely. Solution succeeds best in an Erlenmeyer flask.

Fifteen cc. of the sodium hydroxide solution suffice for one gram of aluminum.

Commercial soda lye may be used if dissolved and filtered through asbestos.

OTHER REAGENTS AND STANDARD SOLUTIONS USED IN ALUMINUM ANALYSIS.

Sodium carbonate, chemically pure.

Soda ash: "Solvay" soda ash, a saturated solution in water, filtered. 
Powdered zinc: Practically free from iron and copper.

Fifteen per cent. nitric wash: (Fifteen parts 1.42 nitric acid to eighty-five parts water).

Standard potassium permanganate: 5.76 grams in two liters. One cc. equals 0.005 grams iron.

Standard potassium cyanide: Forty-five grams in two liters. One cc. is made to equal 0.005 gram coppper.

SPECIAL APPARATUS.

Two narrow glass tubes, graduated roughly, one to hold one gram of powdered zinc and the other one gram of chemically pure sodium carbonate.

The evaporating dishes which are used are, preferably, about four and a half inches in diameter, and are covered with fiveinch glasses.

The Erlenmeyer flasks are of about twelve ounce capacity and furnished with porcelain crucible covers.

THE METHOD.

Determination of Silicon, Iron, and Copper in Commercal Aluminum.-One gram of aluminum drillings is dissolved in a four and a half inch evaporating dish in thirty cc. of "acid mixture." If the drillings are thin it is best to add only fifteen cc. at first. Placing cold water on the cover glass sometimes prevents loss from too energetic foaming. Solution having been completed by warming slightly, evaporate quickly to strong fumes of sulphuric acid and continue heating for five minutes. Experience will show on what parts of the hot plate these solutions can be evaporated without spattering at the time when aluminum sulphate begins to crystallize out. Remove the dishes from the plate by means of an iron fork, and in a few moments add to the contents of each seventy-five to $100 \mathrm{cc}$. of water and ten cc. of twenty-five per cent. sulphuric acid, break up the residue in each dish with a short, heavy glass rod, and place the dishes back on the hot plate. Boil until all aluminum sulphate dissolves. Add to each dish one gram of metallic zinc powder, measured. Be careful to pour the zinc into the middle of the liquid. If it touches the sides of the dish it sometimes 
becomes firmly fixed there. Keep the dish contents at $60^{\circ}$ to $70^{\circ}$ C. until the zinc has dissolved, leaving the iron reduced and the copper precipitated. Filter and wash well with hot water. Cool, titrate the filtrates with standard potassium permanganate. One cc. equals 0.50 per cent. iron when one gram of aluminum has been used. Placing new receivers under the funnels, treat each residue twice with hot fifteen per cent. nitric acid wash. Wash out with water, and in the solutions thus obtained, titrate the copper with standard potassium cyanide, after adding saturated soda ash solution until the precipitated copper carbonate redissolves. The end point of the titration is very satisfactory. The cyanide solution should be standardized with copper of known purity in about the amount usually found, viz., 0.005 to 0.010 gram. The residue of silicon and silica are burned off in numbered crucibles and each fused with one gram of chemically pure sodium carbonate (measured). The crucible containing the fused mass is placed in fifteen cc. of water in the porcelain dish originally used, and twenty-five cc. of twenty-five per cent. sulphuric acid are added. Solution takes place quickly without separation of silica, and after rinsing out and removing the crucible, the solution is evaporated to five minutes fuming on the hot plate. After cooling add seventy-five to Ioo cc. of water and boil to disintegrate the silica. Filter and wash well with water. Burn off and weigh silica and crucible, treat with hydrofluoric acid and a drop of sulphuric acid if impurity is suspected. Evaporate, ignite, and weigh again. Loss equals silica; calculate to silicon.

Determination of Crystalline (Graphitic) Silicon in Aluminum. -Dissolve one gram of aluminum in thirty cc. of thirty-three per cent. hydrochloric acid (two parts of water to one of hydrochloric acid) in a platinum dish; add about two cc. of hydrofluoric acid, stir, and filter at once through a No. o nine $\mathrm{cm}$. filter, contained in a funnel which has been thinly coated with paraffin. Wash with water and burn off in a platinum crucible. Fuse with one gram of sodium carbonate, cool in fifteen cc. of water in a four and a half inch evaporating dish. Add twenty cc. of twenty-five per cent. sulphuric acid. Rinse out the crucible. Evaporate to fumes, cool, add seventy-five cc. of water, 
boil up and filter off the silica. Wash, ignite, and weigh. Calculate to silicon.

The determinations of silicon, copper, and iron are the every day methods of grading aluminum. It is recognized that sodium and carbon occasionally exist in aluminum, and they are determined by methods described. In certain samples it is desirable to know the approximate percentage of graphitic and combined silicon. These determinations are also described. We determine nitrogen, if present, by a special method.

DETERMINATION OF SODIUM IN ALUMINUM.

One gram of drillings is dissolved in a porcelain evaporating dish in fifty cc. of 1.3 sp. gr. nitric acid and sufficient hydrochloric acid to effect solution. Boil down until all hydrochloric acid has been removed. Rinse the solution into a large platinum dish and evaporate to dryness. Heat over a good Bunsen burner until nitric oxide fumes cease to be evolved. Grind the residue finely. Mix it by grinding with one gram of chemically pure ammonium chloride and eight grams of chemically pure calcium carbonate. Heat the mixture in a large covered platinum crucible. For the first fifteen minutes have a Bunsen burner flame just touching the bottom of the crucible, and for the next forty-five minutes, have the whole crucible heated bright red by a full Bunsen burner flame. Cool, and treat the residue with hot, distilled water until it becomes just friable under pressure. Avoid adding an excess of water beyond that necessary to make the sintered mass just friable. Grind it in a wedgewood mortar and rinse out with hot distilled water. Filter, rejecting the well washed residue, and treat the filtrate at the room temperature with saturated ammonium carbonate solution in slight excess. Stir very thoroughly. The precipitated calcium carbonate is at first flocculent, but on standing for about ten minutes, it becomes crystalline. Filter into a platinum dish; reject the residue and evaporate the solution on the water-bath to dryness. Heat carefully to dull redness to expel ammonium salts. Dissolve the residue in a little water and add a few drops of ammonium carbonate solution. If this produces a precipitate, add sufficient ammonium carbonate solution to precipitate all of the 
remaining lime. Stir well, wait ten minutes, filter, evaporate to dryness, heat to dull redness, and weigh sodium chloride. Deduct any sodium chloride found in a blank determination, using acids, etc., as above, and finally eight grams of calcium carbonate and one gram of ammonium chloride.

$$
\mathrm{NaCl} \times 0.39316=\mathrm{Na} .
$$

Care should be taken when heating up the residue of sodium chloride, etc., after evaporating on the water-bath. If the platinum dish and contents are heated for a few minutes on sheet asbestos on the hot plate before placing over the lamp, spattering may be avoided. Sodium is generally absent from aluminum, but it has been found in amounts as high as 0.20 per cent. and is considered a cause of the occasional deterioration of the metal in water.

DETERMINATION OF CARBONIN ALUMINUM. (MOISSAN'S METHOD MODIFIED.)

Triturate two grams of drillings in a Wedgewood mortar with ten to fifteen grams of mercuric chloride, powdered and dissolved, or partly dissolved, in about fifteen cc. of water. Reaction takes place rapidly and a heavy gray residue is left. Persistent trituration removes the last particles of metallic aluminum. Evaporate on the water-bath to dryness. The dry residue is heated in a current of pure hydrogen to expel mercuric compounds. The remaining material is then placed in a boat in a combustion tube and burned off as in carbon determination in steel. The carbon dioxide is caught as barium carbonate, and the excess of barium hydroxide determined by means of standard acid. We are working on a more generally applicable method for carbon in aluminum.

\section{DETERMINATION OF NITROGEN IN ALUMINUM.}

Aluminum, when overheated in re-melting, is believed to have the property of combining with nitrogen. The metal becomes weaker. Moissan's method for determining nitrogen in aluminum may be found in Compt. Rend., I19, I2. Nitrogen thus absorbed would undoubtedly exist as nitride of aluminum and solution of sodium hydroxide with subsequent distillation 
would seem to be the best method of procedure. We are working up this method.

DETERMINATION OF ALUMINUM IN METALIIC ALUMINUM.

Dissolve one gram of metal in thirty cc. of thirty-three per cent. hydrochloric acid in a porcelain dish and evaporated cautiously to complete dryness. Redissolve, by boiling, with ten cc. of concentrated hydrochloric acid and seventy-five cc. of water. Wash into a twelve ounce beaker; dilute to $250 \mathrm{cc}$. and pass hydrogen sulphide until saturated. Filter into a beaker and boil off hydrogen sulphide. Oxidize by adding one $c c$. of concentrated nitric acid and continuing to boil for ten minutes. Cool and make the solution up to $500 \mathrm{cc}$. Remove fifty $\mathrm{cc}$. of the solution, and having diluted to $250 \mathrm{cc}$. and heated to boiling, add ammonium hydroxide in slight excess and boil well for twenty minutes. Let settle; filter, and wash thoroughly with hot water. It is necessary to wash the precipitate off from the filter, break it up, and wash it back again. Finally burn off in a thin-walled platinum crucible, igniting most intensely, and weighing the instant the crucible and content are cool. We have found that alumina is one of the most difficult oxides to dehydrate completely, and when dehydrated it absorbs atmospheric moisture even more rapidly than calcium oxide does. Moissan prefers to precipitate aluminum by ammonium sulphide. Having prepared a solution in hydrochloric acid, he takes an amount equal to 0.15 gram of aluminum, neutralizes it in the cold with armmonia, and precipitates it by ammonium sulphide, which has been recently prepared. He then digests for one hour, filters, washes with hot water, ignites and weighs.

ANALYSIS OF ALIOYS OF ALUMINUM WITH SMALLER AMOLNTS OF OTHER METALS.

Copper Alloys. - Three to thirty per cent. copper, and no zinc or nickel.

Dissolve one-half gram or one gram in fifteen cc. of thirtythree per cent. sodium hydroxide solution in an Erlenmeyer flask of twelve ounce capacity. If the flask is covered and set in a warm place, solution is complete in a few minutes, even if 
the drillings are quite coarse. Dilute to thirty cc. with hot water and filter through a coarse, lintless filter paper (Whitall, Tatum \& Co.'s five inch). Wash well with hot water. Dissolve residue, atter washing it off the filter paper into a twelve ounce beaker, by warming with five cc. of concentrated nitric acid. Cool, add saturated commercial sodium carbonate solution until re-solution occurs. Titrate with standard potassium cyanide solution to the disappearance of the blue color. Standardize the cyanide for about the same amount of copper.

For commercial reasons, twenty per cent. alloys are made in the reduction pots, and these alloys are subsequently used for making copper alloys of low percentage.

DETERMINATION OF NICKEL IN ALUMINUM ALLOYS.

The three per cent. nickel alloy is now used. The addition of three per cent. of nickel increases the tensile strength of aluminum by several thousand pounds per square inch.

One gram of drillings is dissolved in fifteen cc. of thirty-three per cent. sodium hydroxide solution in a twelve ounce Erlenmeyer flask. Dilute to fifty $\mathrm{cc}$. and filter through a five-inch lintless paper, washing the residue thoroughly with hot water. Rinse the residue back into the flask and add three to five cc. of concentrated nitric acid, and a drop of concentrated hydrochloric acid. Boil, and when dissolved, cool, and make up to $250 \mathrm{cc}$. In roo cc. determine the copper by neutralizing with ammonia, adding two cc. of concentrated hydrochloric acid, warming and passing hydrogen sulphide. Filter and wash with ammonium sulphide. Burn it off carefully in a porcelain crucible, and having weighed, dissolve in five cc. of concentrated nitric acid. Then dilute to twenty $c c$, add excess of sodium carbonate solution and titrate with standard potassium cyanide. Boil the filtrate from the cupric sulphide, oxidize with one $\mathrm{cc}$. of nitric acid, and precipitate with ammonium hydroxide. Do not boil, but digest for a few minutes just below the boiling point. Filter, wash, redissolve in hot fifteen per cent. nitric acid wash. Dilute to I5O cc. and again precipitate with excess of ammonium hydroxide, being careful to avoid boiling or prolonged digestion. Filter and wash. Burn off and weigh ferric oxide, etc. In a second 
I00 cc. of the main solution, precipitate nickel hydroxide, cupric oxide, ferric hydroxide, etc., by thirty-three per cent. chemically pure sodium hydroxide solution, added in slight excess to the boiling solution. Boil for fifteen minutes, filter, and wash most thoroughly with hot water. Burn off and weigh nickel oxide, cupric oxide and ferric oxide. Deduct cupric oxide and ferric oxide already found. Calculate nickel oxide to metallic nickel.

ANALYSIS OF ALUMINUM-MANGANESE ALLOYS.

Determination of Manganese.-Place one gram of drillings in a twelve ounce beaker. Add thirty cc. of thirty-three per cent. hydrochloric acid (one part of concentrated hydrochloric acid to two of water). When dissolved, add twenty-five cc. of nitric acid (I.42), and boil down to ten cc. Add fifty cc. of colorless nitric acid (I.42) and boil. Precipitate the manganese with powdered potassium chlorate, added cautiously, and proceed as described under manganese in steel by Williams' method. ${ }^{1}$

ANALYSIS OF CHROMIUM-ALUMINUM ALIOY.

Determination of Chromium.-Dissolve one gram in a twelve ounce beaker in thirty cc. of thirty-three per cent. hydrochloric acid, and when dissolved add fifty cc. of sulphuric acid (I.84), and evaporate carefully until fumes of sulphur trioxide escape. Cool, add sixty cc. of water and boil. After five minutes, if all aluminum sulphate has been dissolved, add powdered potassium permanganate until the solution has a distinct pink color. Boil until the excess of potassium permanganate is decomposed. Filter through washed asbestos and determine the chromium in the filtrate as in chrome steel. ${ }^{2}$

ANALYSIS OF TUNGSTEN-ALUMINUM ALLOY.

Determination of Tungsten.-Dissolve one gram in thirtythree per cent. hydrochloric acid in a four and a half inch evaporating dish. Add thirty cc. of nitric acid (1.42) and evaporate to dryness. Redissolve in thirty cc. of hydrochloric acid (I.20), dilute to about ninety cc., and boil for two hours. Filter and wash thoroughly. Burn off and weigh $\mathrm{Si}+\mathrm{SiO}_{2}+\mathrm{WO}_{3}+$ crucible. Treat with three drops of twenty-five per cent. sul-

1 Blair's "Chemical Analysis of Iron."

2 Galbraith's Method. See Blait's "Chemical Analysis of Iron." 
phuric acid and about two cc. of hydrochloric acid. Evaporate carefully over an Argand burner, re-ignite, and weigh crucible and silicon and tungstic oxide. Fuse with one gram of sodium carbonate, cool, place in dish, and add fifteen cc. of water and twenty cc. of twenty-five per cent. sulphuric acid, remove crucible and evaporate until white fumes escape. Cool, redissolve in about fifty cc. of water. Filter, wash, ignite, and weigh silica (from silicon), tungstic oxide, and crucible. Treat with sulphuric acid and hydrofluoric acid, evaporate, ignite, and reweigh. Loss equals silica. Calculate to silicon and add to the weight of silica lost by treatment of first insoluble residue. Deduct this sum from the weight of silicon, silica, and tungstic oxide first found and the remainder equals tungstic oxide. Calculate to tungsten.

ANALYSIS OF ALUMINUM-TITANIUM ALLOY.

Determination of Titanium.-Two grams of the alloy in a twelve ounce Erlenmeyer flask are dissolved by addition of fifty cc. of ten per cent. potash solution. Dilute with distilled water to about $125 \mathrm{cc}$, boil up, and filter as quickly as possible. Wash ten times with boiling water. Burn off the residue in a porcelain crucible, crush it in a Wedgwood mortar, fuse in a large platinum crucible with ten grams of potassium bisulphate. Conduct the fusion exactly as follows: Choose a good Bunsen burner, and protect it from draught by a sheet-iron chimney; make the flame one and a half inches long, and place the triangle carrying the upright crucible just at the point of the flame. Increase the heat gradually until in ten minutes the lower fourth of the crucible is red hot. Allow it to remain at this temperature ten minutes, moving the lid slightly to one side every two minutes, and giving the crucible (held firmly in the tongs) a gentle rotating movement, then turn up the light until the flame reaches the top of the crucible and envelopes it. Five minutes of this treatment melts down any potassium bisulphate, etc., which have risen on the sides. The flame is lowered and the lower fourth heated for ten minutes longer. Cool, dissolve in about $200 \mathrm{cc}$. of water; filter, rejecting the residue, if ignition and treatment with hydrofluoric acid show it to be only silica. 
If it contains anything more, fuse with four grams of potassium bisulphate again. The filtrate contains all the titanic oxide and the ferric oxide. Add ammonia until a slight permanent precipitate is formed, then add dilute sulphuric acid from a pipette or burette until this precipitate just redissolves. Finally add one cc. more of twenty-five per cent. sulphuric acid and dilute to $300 \mathrm{cc}$. If the solution is high in iron (which will be indicated by its distinct yellow color) sulphur dioxide gas must be run into it until it is decolorized and smells strongly of sulphur dioxide, but if the solution is nearly colorless, indicating a low percentage of iron, only sulphur dioxide water need be added for the reduction. Boil well for one hour, adding water saturated with sulphur dioxide occasionally. Filter off the titanic oxide through double filters and wash well with hot water. Burn off and weigh as titanic oxide. If the precipitate is yellow, indicating the presence of iron, it may be fused with one gram of potassium bisulphate, the fusion dissolved in ten cc. of dilute sulphuric acid, and the iron determined in this solution by reducing with one gram of zinc, and titrating with permanganate. This is not often necessary. Calculate titanic oxide to titanium. $\mathrm{TiO}_{2} \times 0.6=\mathrm{Ti}$.

DETERMINATION OF ZINC IN ZINC-ALUMINUM ALLOY. FIRST METHOD.

Dissolve one gram in thirty cc. of thirty-three per cent. hydrochloric acid in a twelve ounce beaker. Dilute to $200 \mathrm{cc}$. and heat nearly to boiling. Pass hydrogen sulphide till all copper is precipitated. Filter and boil off hydrogen sulphide, oxidize with one cc. nitric acid by boiling ten minutes. Add sodium hydroxide solution until neutral, then make barely acid with hydrochloric acid, and stir until the aluminum hydroxide all dissolves. Add ten grams of sodium acetate and $500 \mathrm{cc}$. of water, boil up, and filter at once. Dissolve the washed precipitate in hydrochloric acid and repeat the acetate separation. Heat the united filtrates to boiling and pass hydrogen sulphide. Filter off the zinc sulphide on double filters, wash thoroughly with hot water. Burn off in a porcelain crucible, and weigh zinc oxide. Calculate to zinc. This method may be used when 
only a small quantity of the sample is available, but when this is not the case, it is better to use the method given below.

\section{DETERMINATION OF ZINC IN ZINC-ALUMINUM ALLOYS. SECOND METHOD.}

Dissolve one gram of drillings in thirty-three per cent. sodium hydroxide solution in a twelve ounce Erlenmeyer flask. Filter as soon as dissolved through a four inch lintless filter paper. Wash thoroughly with hot water. Rinse the residue of zinc, iron, copper, silicon, etc., back into the flask. This may require $25 \mathrm{cc}$. of water. Add five cc. of hydrochloric acid and boil. Dilute to $150 \mathrm{cc}$. with hot water and pass.hydrogen sulphide. Filter and boil off hydrogen sulphide, reoxidize by adding one cc. nitric acid and boiling ten minutes. Add sodium hydroxide till neutral, then add dilute hydrochloric acid till just acid, and then ten grams of sodium acetate, and $300 \mathrm{cc}$. of boiling water, and boil for five minutes. Wash well. If the precipitate is small, resolution and reprecipitation are not necessary. Pass hydrogen sulphide through the filtrate. Filter off zinc sulphide through double filters. Wash well. Ignite in a porcelain crucible, heating finally over the blast, to zinc oxide. $\mathrm{ZnO} \times$ $0.8032=\mathrm{Zn}$.

ANALYSIS OF ALUMINUM SOLDERS.

Determination of Tin, Phosphorus, and Zinc.-Aluminum solders generally contain phosphor-tin, and zinc. As presented for analysis, they usually consist of a soldered joint, from which the solder must be scraped and analyzed. The analysis, therefore, involves a separation of the elements aluminum, zinc, tin, and phosphorus. It is a difficult matter to determine whether aluminum was a constituent of the solder when only a soldered joint is available for examination. It is best to dissolve all adhering aluminum from the pieces chosen for analysis by treatment with thirty-three per cent. sodium hydroxide solution after which the residue is filtered off, dried, and weighed out for analysis. Dissolve or decompose three-tenths to five-tenths gram in a twelve-ounce beaker by means of twenty cc. of nitric acid (1.42). If necessary, five cc. of hydrochloric acid (I.2) may be used to effect complete decomposition. Evaporate to 
complete dryness on a hot plate. Cool, add twenty-five cc. of nitric acid (I.I3), and boil thoroughly. Filter. The residue contains all of the tin, most of the phosphorus, and possibly some zinc. Burn it off in a porcelain crucible and, after pulverizing the residue in an agate mortar, mix it with two grams of sodium carbonate and two grams of sulphur, fuse it in a covered porcelain crucible over a Bunsen burner for about half an hour. Give it three minutes of gentle blast flame at the last. Cool, boil out with $50 \mathrm{cc}$. of water in a twelve-ounce covered beaker. Filter and wash. Extract any possible zinc sulphide, etc., from the residue, by dissolving in nitric acid, boiling off hydrogen sulphide, and adding this to the first filtrate obtained after evaporating to dryness with nitric acid. The sodium sulphide solution contains the tin and phosphorus. Add to it hydrochloric acid until just acid. Warm slightly and pass hydrogen sulphide. Filter off stannous sulphide and wash thoroughly with hot water. Burn off in a porcelain crucible and weigh stannic oxide. Calculate to metallic tin. The filtrate from the stannous sulphide is boiled to expel hydrogen sulphide and then oxidized by adding two cc. of nitric acid and boiling for fifteen minutes more. Filter off any sulphur which separates, and in this filtrate, which should amount to ouly about Ioo cc., precipitate the phosphorus by adding pure sodium hydroxide solution till alkaline, then nitric acid till distinctly acid, heating to $85^{\circ} \mathrm{C}$., and adding fifty cc. of filtered molybdate solution. Stir or shake well for five minutes, filter on a weighed filter paper, and after washing with one per cent. nitric acid wash, dry at $100^{\circ} \mathrm{C}$. and weigh. Yellow precipitate multiplied by 0.0163 equals phosphorus. The nitric acid solution obtained after evaporating the first solution to dryness, etc., is now neutralized with sodium hydroxide solution, and then made just acid with hydrochloric acid. Ten grams of sodium acetate are now added, and $300 \mathrm{cc}$. of water (hot). Boil up for five minutes, then filter and wash. If the precipitate is of considerable size, it is probable that aluminum was a constituent of the solder. Redissolve it in a little hydrochloric acid, neutralize, acidify, and make a basic acetate separation as before. Precipitate the zinc in the acetate solutions by hydrogen sulphide. 
Filter, wash, ignite in a porcelain crucible, and weigh as zinc oxide. Calculate to metallic zinc. Dissolve the precipitate of aluminum acetate in hydrochloric acid, dilute to $250 \mathrm{cc}$, and precipitate with ammonia. After filtering, washing, igniting, and weighing as alumina, calculate to metallic aluminum. Solders containing lead are sometimes met with. In such cases, evaporate the nitric acid filtrate from the metastannic acid to small bulk, add twenty-five cc. of twenty-five per cent. sulphuric acid, and evaporate until white fumes escape. Cool, add roo cc. of water, stir, and let stand for an hour in a warm place. Filterand wash with water containing five per cent. of sulphuric acid. Burn off in a porcelain crucible at a low temperature. Reoxidize any reduced lead oxide and restore its sulphur trioxide by adding a few drops of nitric acid and sulphuric acid and evaporating. Finally weigh lead sulphate. Calculate to metallic lead. Zinc is determined in the lead sulphate filtrate.

\section{ANAIYSIS OF ALUMINA.}

Alumina is made from bauxite or cryolite. It is usually purchased in the hydrated form.

HYDRATED ALUMINA.

Hydrated alumina is analyzed for water, silica and sodium carbonate.

Water.-Ignite one gram in a closely covered crucible, at first gently and then intensely for fifteen minutes over the strongest blast. The loss on ignition includes water and the carbon dioxide of the sodium carbonate. Calculate the carbon dioxide from the sodium oxide found and deduct it from the loss on ignition.

Silica. - Hydrated alumina is soluble in sulphuric acid of $42^{\circ}$ B. The silica, however, is left undissolved. $42^{\circ} \mathrm{B}$. sulphuric acid is made by mixing $900 \mathrm{cc}$. of concentrated sulphuric acid with $1290 \mathrm{cc}$. of water. Five grams of hydrated alumina are treated with twenty-five cc. of $42^{\circ} \mathrm{B}$. sulphuric acid and heated until the alumina appears to be all dissolved. Dilute to Ioo cc. and boil. Filter, wash, ignite and fuse the residue with one gram of potassium bisulphate and cool. Dissolve in water, filter, wash, ignite, and weigh in cru- 
cible, treat with sulphuric acid and hydrofluoric acid, evaporate, ignite and weigh again. Loss equals silica.

Soda.-The method for the determination of soda is the same in calcined and hydrated alumina. The method is that of J. L. Smith, and is described under "Sodium in Aluminum." Calculate sodium chloride to sodium carbonate, if the sample is hydrated, and to sodium oxide if the sample is calcined alumina.

\section{CALCINED ALUMINA.}

Water and soda are determined as in hydrated alumina.

Silica.-Fuse one gram of the finely ground alumina with ten grams of potassium bisulphate. If this does not make a clear fusion add two grams of bisulphate and heat up again. Dissolve the fusion when cool in water and filter. Burn off the insoluble residue. Fuse it with one gram of sodium carbonate and cool in fifteen cc. of water in a four and a half inch evaporating dish. Add twenty-five $c c$. of twenty-five per cent. sulphuric acid. When all soluble matter has dissolved, remove the crucible and evaporate down until sulphuric acid fumes escape. Cool, dilute with water, boil, filter, ignite, and weigh silica plus crucible, treat with sulphuric and hydrofluoric acids, and weigh again. Loss equals silica.

\section{ANALYSIS OF BAUXITE.}

Method adopted, May, 1895 .

No unusual apparatus or reagents are required.

One and five-tenths grams of very finely ground bauxite (previously dried at $100^{\circ} \mathrm{C}$. and bottled), is taken for analysis. Weigh into a five inch porcelain evaporating dish and dissolve in fifty cc. of acid mixture. This mixture is the same as that used for aluminum analysis. Boil the solution down until fumes escape and keep the residue fuming strongly for about fifteen minutes. Cool, add Ioo cc. of water, stir and then boil for ten minutes. Filter, wash well with water, receiving the filtrate in a beaker of about $300 \mathrm{cc}$. capacity. The filtrate and washings should amount to about $175 \mathrm{cc}$. Burn off the insoluble residue (which consists chiefly of silica, with a little titanic acid, oxide of iron, and alumina) and weigh it in the crucible, add three drops of twenty-five per cent. sulphuric acid and about five cc. of hydro- 
fluoric acid and evaporate slowly to dryness. Ignite very strongly and weigh. The loss in weight equals silica. Add to the residue in the crucible one gram of potassium bisulphate and fuse quickly and thoroughly over a Bunsen burner, cool and place the crucible in the beaker containing the main sulphuric acid solution. The small residue from this fusion will be silica, and is to be added to the silica already found. Having obtained the sulphate solution containing all the alumina, ferric oxide and titanic oxide, make it up to $55^{\circ} \mathrm{cc}$. and mix. Then fifty cc. will equal three-tenths gram bauxite. Take fifty cc. and dilute to $300 \mathrm{cc}$. Add two cc. of conceitrated hydrochloric acid and ammonia in slight excess, boil for five minutes, let the precipitate settle, filter and wash very thoroughly with hot water. Test the filtrate for further alumina by boiling. Burn off the filter paper and ignite the precipitate very strongly after crushing all the lumps of alumina. Weigh alumina, ferric oxide and titanic oxide.

Titanic Acrd.-Take Ioo cc. of the original sulphate solution (six-tenths gram), add ammonia until a slight permanent precipitate is formed, then add sulphuric acid from a pipette or burette until this precipitate just redissolves. Finally add one cc. more of twenty-five per cent. sulphuric acid and dilute to $400 \mathrm{cc}$. If the bauxite is high in iron (which will be indicated by the distinct yellow color of this solution) sulphur dioxide gas must be run into it until it is decolorized and smells strongly of sulphur dioxide, but if the solution is nearly colorless, indicating a low percentage of iron, only sulphur dioxide water need be used for the reduction. Boil well for one hour, adding water saturated with sulphur dioxide occasionally. Filter off the titanic oxide through double filters and wash well with hot water. If the precipitate is yellow, indicating the presence of iron, it can be fused with one gram of potassium bisulphate, the fusion dissolved in water, and the iron determined in this solution by reducing with zinc and titrating with permanganate. This is not often necessary.

Oxide of Iron.-Take fifty cc. of the sulphate solution, add ten cc. of dilute sulphuric acid and one gram of granulated zinc, 
and set the beaker in a warm place. When reduced, filter and titrate the iron with standard potassium permanganate. More zinc is used for bauxites high in iron.

METHOD FOR IRON DETERMINATION, USING A LARGER QUANTITY OF BAUXITE. (APPLICABLE TO PUREST ORES).

Place a half gram of the finely powdered ore in a large platinum crucible and add three cc. of twenty-five per cent. sulphuric acid and five cc. of hydrochloric acid, and evaporate very slowly to fumes; drive off the excess of sulphuric acid by heat, boil out the residue with water and add ten $c c$. of dilute sulphuric acid. Remove the crucible and reduce with zinc, as above, and titrate.

Water and Organic Matter.-Ignite three-tenths gram, cautiously at first and finally very strongly in a covered crucible. The loss of weight equals water and organic matter.

\section{ESTIMATION OF THORIA. CHEMICAL ANALYSIS OF MONAZITE SAND.}

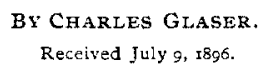

SINCE the introduction of the Auer-Welsbach light, the com- mercial importance of monazite sand has grown greatly, and chemists are now asked to determine the percentage of true monazite, and especially that of thoria, in samples of the sand. This has heretofore been accomplished indirectly; the quantities of iron, titanium and silica were determined and the remainder of the material calculated as monazite. A sample treated in this manner gave the following results :

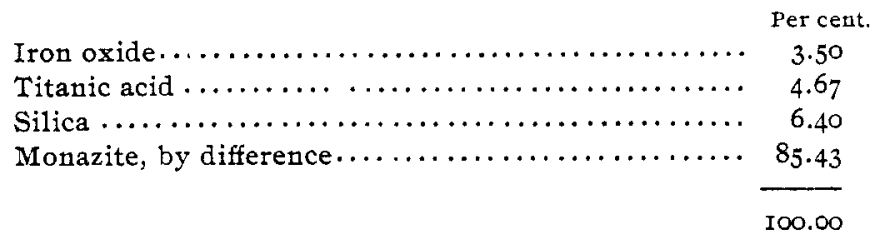

The sample contained $18.3^{8}$ per cent. phosphoric acid, which calculated as cerium phosphate (factor 3.32) equals 6r.ro per cent.

From analyses printed in Dana's Mineralogy, it was inferred 